intended leaving their job in the near future ... six months later ... eight staff members $(23 \%)$ have left their jobs in the day hospital and two hostel staff retired." (p. 805)

Main (1980) has put the social perspective in:

"Every human organisation is a social and interpersonal setting that either extends or cramps the personality of those within it, and is variously therapeutic or antitherapeutic, creating increased or decreased health".

Their described situation cramp staff and patients, is anti-therapeutic, and creates decreased health. The social atmosphere does not tolerate the eccentrics, their staff, nor their interpersonal relationships.

HaIleY, A. M. (1971) Long-stay psychiatric inpatients: a study based on the Camberwell register. Psychological Medicine, 1, 128-142.

LINDSAY, J. S. B. (1962) Trends in mental-hospital population and their effect on planning. Lancet, 23rd June.

MAIN, T. (1980) Some basic concepts in therapeutic community work. In The Therapeutic Community (ed. E. Jensen) p. 52. London: Croom Helm.

TOOTH, G. C. \& BROOKE, E. M. (1961) Trends in the mental hospital population and their effect on future planning. Lancet, 1 April, 710-713.

Unit 1,60 Broadway

JOHN LINDSAY

Nedlands, 6009

Western Australia

\section{Depression of old age}

SIR: Baldwin et al (Journal, July 1993, 163, 82-90) challenge the notion that cerebral disease is an indicator of poor prognosis in the depression of old age. They report only a trend for those with putative cerebral disease to do worse than those assumed not to have cerebral disease.

Cognitive impairment has long been equated with cerebral disease but the reverse cannot be said to be true. Kobari et al (1990) found $21.6 \%$ of cognitively normal volunteers to have leuko-araiosis. When cardiovascular risk factors are excluded, this figure falls dramatically (Kozachuck et al, 1990).

Steingart et al (1987) report that cognitively normal people with leuko-araiosis are significantly more likely to have neurological soft signs than those that have none. Fein et al (1990) have reported normal cognitive functioning of elderly subjects with extensive white matter lesions over a period of seven years.

Neuroimaging is clearly the gold standard in this area. If this is impractical then a detailed neurological assessment with an eye to soft signs needs to be undertaken and reported. There is also a suggestion that cardiovascular risk factors should be investi- gated in a similar way. Without taking these into account it is likely that a considerable number of subjects will be wrongly allocated to a functional rather than an organic group. It may be that this failure explains why the results do not bear out those of previous studies.

The important point to emerge from this study is, however, that the treatment of depression in the elderly, of both a functional and organic aetiology, is a worthwhile exercise and should be pursued vigorously within the patients' tolerance.

Fein, G., VAn Dyke, C., Da venport, L., et al (1990) Preservation of normal cognitive functioning in elderly subjects with extensive white-matter lesions of long duration. Archives of General Psychiatry, 47, 220-223.

KobarI, M., MeYer, J. S. \& IChuo, M. (1990) Leuko-araiosis, cerebral atrophy and perfusion in normal aging. Archives of Neurology, 47, 161-165.

Kozachuk, W. E., DeCarl, C., Schapiro, M. B., et al (1990) White matter hyperintensities in dementia of Alzheimer type and in healthy subjects without cerebrovascular risk factors. Archives of Neurology, 47, 1306-1310.

Steingart, A., Hachinski, V. C., LAu, C., et al (1987) Cognitive and neurological findings in subjects with diffuse white matter lucencies in computed tomographic scan (leuko-araiosis). Archives of Neurology, 44, 32-35.

Hither Green Hospital

Christopher Ball

Hither Green Lane

London SE13 6RU

\section{Ageing as a risk factor for lithium neurotoxicity at} therapeutic serum levels

SIR: In their recent report of patients with lithiuminduced neurotoxicity, Bell et al (Journal, May 1993, $162,689-692$ ) discussed several factors known to increase the risk of toxicity with therapeutic levels of lithium. However, the authors did not mention older age as a possible predisposing factor.

Since ageing alters receptor-site sensitivity, it is hypothesised that the elderly are more sensitive to the side-effects of lithium. Indeed, there are data to support this hypothesis: firstly, the prevalence and severity of hand tremor in lithium-treated patients increases with age (Murray et al, 1983); secondly, Roose et al (1979) and Smith \& Helms (1982) found that, at therapeutic blood levels, people 60 years and over had more lithium toxicity, including neurotoxicity, than younger patients. However, these two studies did not control for confounding variables, such as concomitant psychotropic use. There have also been several reports (for example, Lafferman et al, 1988; Austin et al, 1990) of cognitive impairment, ataxia, extrapyramidal signs, disabling tremor, peripheral nerve palsy, and aphasia developing in 
elderly patients with refractory depression undergoing lithium augmentation, despite therapeutic doses of lithium and antidepressants. It is possible that, compared with younger patients, the elderly are at greater risk of toxicity with a lithiumantidepressant combination (Austin et al, 1990), although a comparative study has not been undertaken.

Thus, although the data are limited and not conclusive, the elderly appear to be at increased risk of lithium toxicity at therapeutic blood levels. Given that neurotoxicity can develop without other sideeffects of lithium (Smith \& Helms, 1982), and its varied presentation may mimic neurological conditions associated with ageing, one needs to maintain a high index of suspicion when prescribing lithium in this patient population.

Austin, L. S., Arana, G. W. \& Melvin, J. A. (1990) Toxicity resulting from lithium augmentation of antidepressant treatment in elderly patients. Journal of Clinical Psychiatry, 51, 344-345.

LAFrerman, J., SOLOMON, K. \& RUSKIN, P. (1988) Lithium augmentation for treatment-resistant depression the elderly. Journal of Geriatric Psychiatry and Neurology, 1, 49-52.

Murray, N., HopwOOd, S., BAlpoUR, D. J. K., el al (1983) The influence of age on lithium efficacy and side-effects in outpatients. Psychological Medicine, 13, 53-60.

Roose, S. P., Bone, S., Haidorfer, C., et al (1979) Lithium treatment in older patients. American Journal of Psychiatry, 136, 843-844.

Smith, R. E. \& Helms, P. M. (1982) Adverse effects of lithium therapy in the acutely ill elderly patient. Journal of Clinical Psychiatry. 43, 94-99.

Toronto General Hospital

Alastair Flint

Toronto

Canada MSG 2 C4

Higher risk groups and paracetamol overdose

SIR: Prescribers Journal recently carried a very important article on paracetamol overdoses (Ferner,
1993). One paragraph, in particular, bears repetition in a psychiatric journal such as this:

"Certain patients, particularly chronic alcoholics or those who take enzyme inducing drugs such as phenytoin and carbomazepine, are at higher risk of paracetamolinduced hepatic neurosis, and should be treated at plasma paracetamol concentrations half as great as those indicated by the standard treatment graph."

This is not standard knowledge, and is obviously worth bearing in mind when being referred patients from casualty or medical wards.

Ferner, P. (1993) Paracetamol poisoning - an update. Prescribers Journal, 33, 2.

\section{Chiltern Day Hospital}

Cotswold Road

Sutton SM2 5NF

\section{Double firing of ECT machine}

SIR: We wish to report three instances when there was double firing of an Ectronus Series 5 Constant Current electroconvulsive therapy (ECT) machine over a period of six months. On each occasion the machine was fully serviced and no cause could be found. This problem never occurred with our old Duopulse Constant Current ECT machine.

It is apparently possible to produce a double firing if one depresses the fire button of the hand-held electrode, and then releases it at the end of the shock. We were able to do this while investigating the problem, but are unable to confirm if this was the cause. Attention to this aspect of administration has meant no recurrence of the problem in the subsequent six months.

R. W. B. Athawes

J. Graham

Crichton Royal Hospital

Dumfries DGI 4TG

\section{A HUNDRED YEARS AGO}

\section{Some lessons of suicide}

Few of the misfortunes which can overtake a man are able so to overwhelm him that they do not leave open some avenue of hope, and the more especially if they are not attributable to conscious error on his part. The mind so conquered by depression that it cannot see this outlet is therefore surely unhealthy. It may doubtless be free from other ordinary signs of persistent and confirmed insanity, but it illustrates, never- theless, a condition of weakness which in the grosser bodily fabric would pass for disease. Its disorder is not less a malady because it is often transient and is not related to known organic changes. In it we recognise the close connexion between rational and moral qualities, and it is the failure of both, but especially the latter, to influence their unfortunate possessor which is so grimly taught by suicide. Despair is the true exciting cause of such calamities, and this we take it is nothing else than moral short sight. We are 